
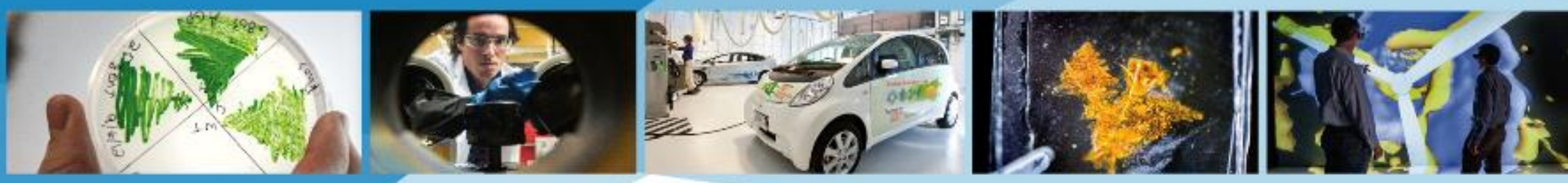

\title{
Using Residential Solar PV Quote Data to Analyze the Relationship Between Installer Pricing and Firm Size
}

Eric O'Shaughnessy

Robert Margolis

May 2017

NREL/PR-6A20-68153 
We use residential solar photovoltaic (PV) quote data to study the role of firm size in PV installer pricing. We find that large installers (those that installed more than 1,000 PV systems in any year from 2013 to 2015) quote higher prices for customer-owned systems, on average, than do other installers. The results suggest that low prices are not the primary value proposition of large installers. 
- Introduction

- Data and Methods

- Results

- Discussion

- Conclusion 


\section{Introduction: Market Context}

- The vast majority of U.S. residential PV installers are small local firms, yet a few large national-scale installers dominate this industry.

- What are the effects of this market concentration?

- Do large installers achieve economies of scale (lower costs with increasing volume) and offer lower prices to customers? (Cost reduction hypothesis)

- Do large installers use their size to exercise market power and charge higher prices? (Market power hypothesis) 


\section{Introduction: The Market Power Hypothesis}

- PV markets are imperfectly competitive, customers generally only obtain a limited number of quotes.

- Market power refers to the ability of firms to earn above-cost returns owing to imperfect competition.

- Several studies provide some evidence of market power in the PV installation industry (Gillingham et al. 2016, Nemet et al. 2017, Pless et al. 2017), possibly attributable to lack of price transparency and customer familiarity with PV. 


\section{Introduction: The Cost Reduction Hypothesis}

- Even in the presence of some market power, prices should roughly reflect production costs.

- Large installers may be able to reduce costs through economies of scale and "learning by doing" and pass these cost reductions through to customers as lower prices.

- Several studies (Gillingham et al. 2016, Nemet et al. 2017, Pless et al. 2017) indicate that more experienced installers offer lower prices. 


\section{Introduction: Our Approach}

- Most PV price studies to date have relied on installed system price data.

- We use PV quote data, rather than installed system prices, to study the effects of firm size on installer pricing.

- Using quote data allows us to compare prices for systems quoted to the same customer, effectively controlling for customer-level differences.

Installed Price Approach

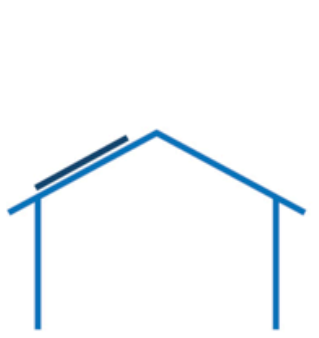

\$/W

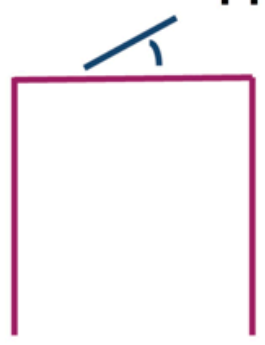

$\$ / \mathrm{W}$

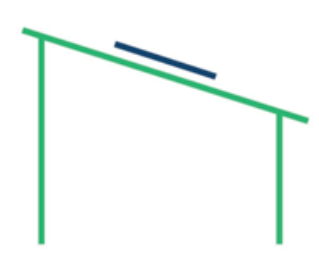

$\$ / \mathrm{W}$

Installed system prices are compared across multiple systems. System- and site-level differences are controlled for to the extent possible. Some unobservable site-level differences may bias the results.

Quote Price Approach

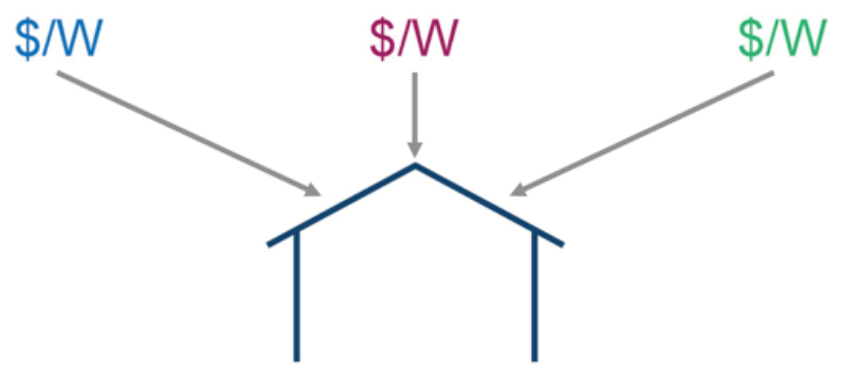

Prices are compared across multiple quotes made to the same customer. System differences between the quotes are controlled for to the extent possible. Site-level differences are automatically controlled for given that the quotes are made to the same customer.

\section{Installed Price Approach Compared with Quote Price Approach}


- We use residential PV quote data from the thirdparty quote provider EnergySage.

- Some EnergySage customers also voluntarily upload quotes received outside of the EnergySage network, referred to as "external" quotes.

- We exclude quotes with no system purchase option (about $5 \%$ of quotes) to allow for comparisons based on a quoted system purchase price.

- The full dataset consists of 1,588 quotes made to 351 customers in 27 states and Washington, DC, from February 2014 to October 2016. 


\section{Methods: Paired Difference Approach}

- We define a "large installer" as any installer with $>1,000$ systems installed in any given year from 2013 to 2015 (based on data from Barbose and Darghouth 2016).

- For each customer, large installer quotes are paired with nonlarge installer quotes to calculate a "paired difference."

A large installer provides a quote to a customer

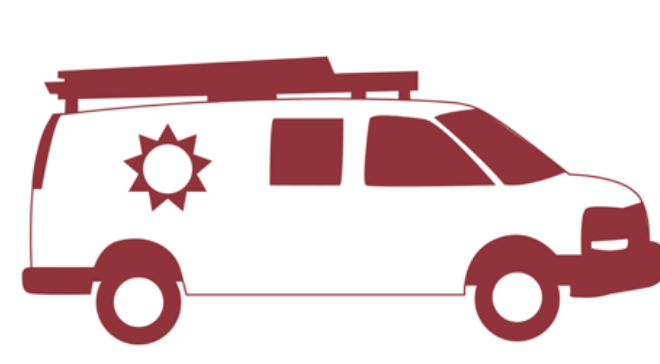

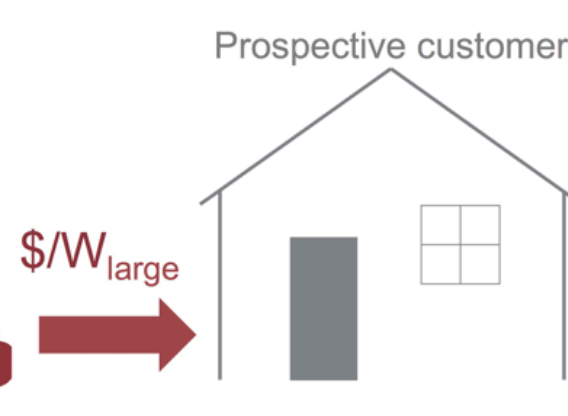

A non-large installer provides a quote to the same customer

These quotes are "paired" to calculate a paired difference (D):

$$
D=\$ / W_{\text {large }}-\$ / W_{\text {non-large }}
$$

The paired difference t-test evaluates the statistical significance of many of these differences $\left(D_{1}+D_{2}+D_{3}+D_{4}+\ldots\right)$ in quotes between large and non-large installers to the same customers.

Schematic of Paired Difference Approach 


\section{Methods: Paired Difference Approach}

Let $D_{i}$ represent the difference in quote prices between a large installer quote and a non-large installer quote made to customer $i$ :

$$
D_{i}\left(\frac{\$}{W}\right)=\text { large installer quote } e_{i}\left(\frac{\$}{W}\right) \text { - non large installer quote } e_{i}\left(\frac{\$}{W}\right)
$$

Consistently positive/negative values of $D$ could suggest that large installer quotes are generally higher/lower than non-large installer quotes. We explore the existence of a trend through the following hypothesis test:

Null hypothesis: No systematic difference (D) between large and non-large installer quotes

$$
H_{0}: D=0
$$

Alternative hypothesis: Large and non-large installer quotes vary systematically

$$
\boldsymbol{H}_{\boldsymbol{A}}: D \neq \mathbf{0}
$$

We test this hypothesis with a paired difference $t$ test $(\bar{D})$ :

$$
t_{D}=\frac{\bar{D}}{S E(\bar{D})}
$$

Where $\bar{D}$ is the sample mean of paired differences and $S E(\bar{D})$ is the standard error of paired differences. 


\section{Results: Descriptive Statistics}

Within our entire dataset, average large installer quotes are about $\$ 0.37 / \mathrm{W}$ higher than average non-large installer quotes.

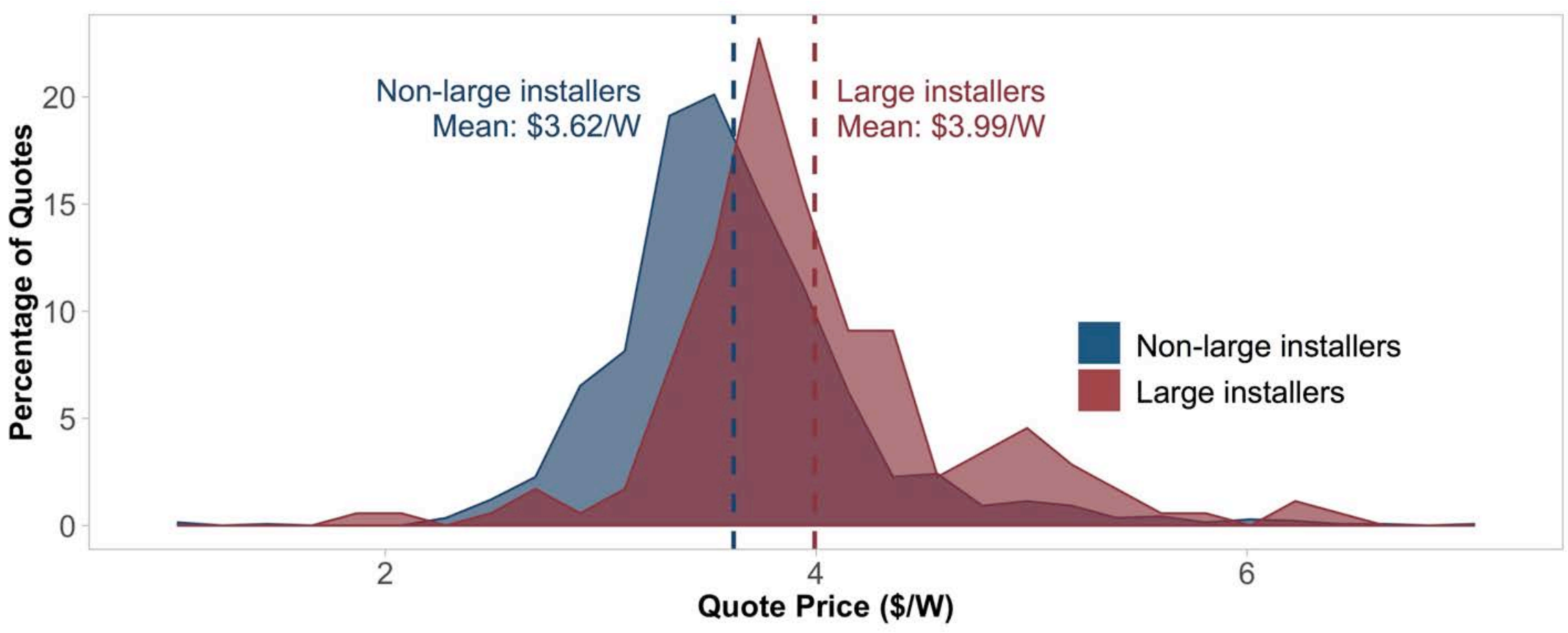

Quote Price Distributions for Large and Non-Large Installers, Full Dataset 


\section{Results: Paired Difference Raw Quote Price Approach}

- Our paired dataset provides 707 unique pairings of large and non-large installer quotes made to 142 customers. Large installer quotes are about $\$ 0.33 / \mathrm{W}(10 \%)$ higher than corresponding non-large installer quotes, on average. This difference is statistically significant $(t=11.6)$.

- The large installer quote is higher than the corresponding non-large installer quote in about $70 \%$ of pairings.

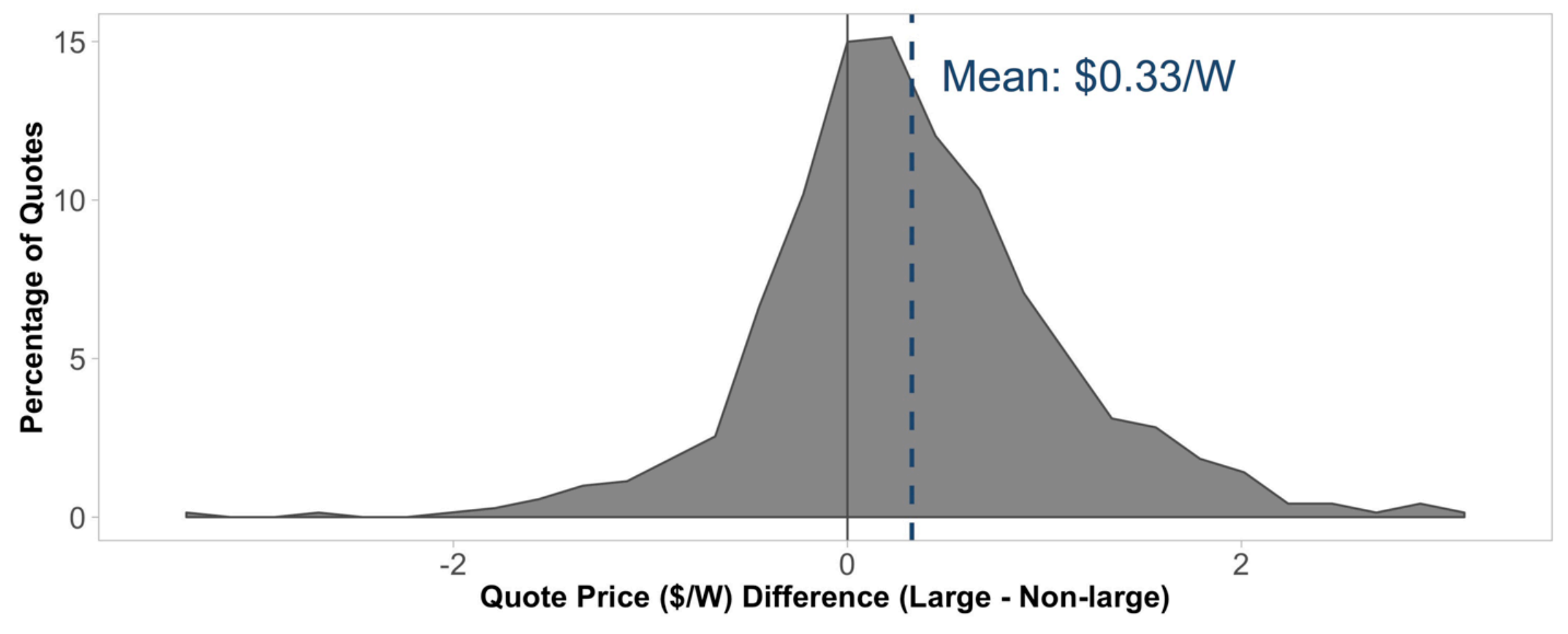

Paired Difference Distribution 


\section{Results: Controlling for Systematic Variation}

- Large installer quotes vary from non-large installer quotes in several ways that could affect system prices.

- We control for these potentially confounding factors to avoid spurious conclusions about the effect of firm size.

Average System Characteristics for Large and Non-Large Installers

\begin{tabular}{lcc}
\hline & Large Installers & Non-large Installers \\
\hline Price $(\$ / \mathrm{W})$ & 3.99 & 3.62 \\
System size $(\mathrm{kW})$ & 6.9 & 7.8 \\
Quote date & $4 / 2 / 2016$ & $4 / 17 / 2016$ \\
$\%$ external & $62 \%$ & $14 \%$ \\
Module efficiency $(\%)$ & $16.1 \%$ & $16.1 \%$ \\
$\%$ using micro-inverters & $38 \%$ & $33 \%$ \\
$\%$ using optimizers & $10 \%$ & $46 \%$ \\
\hline
\end{tabular}




\section{Results: Model to Control for Systematic Variation}

$$
Q_{i}=\beta_{0}+\beta_{1} \text { size }_{i}+\beta_{2} \text { size }_{i}^{2}+\beta_{3} \text { date }_{i}+\beta_{4} \text { eff }_{i}+\beta_{5} \text { micro }_{i}+\beta_{6} \text { optim }_{i}+\beta_{7} \text { ext }_{i}+\epsilon_{i}
$$

- $Q_{i}$ is the quote price for quote $i$

- size $_{i}$ and size $_{i}^{2}$ are the system size and system size squared

- date $_{i}$ is the quote date

- $e f f_{i}$ is the efficiency of the installed module (used as a proxy for equipment quality)

- micro $_{i}$ is a dummy variable for whether the system used a micro-inverter

- optim $_{i}$ is a dummy variable for whether the system used an optimizer

- $e x t_{i}$ is a dummy variable for whether the quote was made through EnergySage (ext $=0$ ) or outside $($ ext $=1)$

- $\epsilon_{i}$ is a residual term for quote $i$

- the terms $\beta$ are the coefficients in the model.

We use the residual term to create a difference metric that controls for potentially confounding factors:

$$
D_{i}^{\epsilon}=\text { large installer } \epsilon_{i}-\text { non large installer } \epsilon_{i}
$$




\section{Results: Paired Difference Residuals Approach}

On average, large installer quotes are $\$ 0.19 / \mathrm{W}$ higher than predicted by the model $(\epsilon=0.19)$, while non-large installer quotes are $\$ 0.02 / \mathrm{W}$ lower than predicted by the model $(\epsilon=-0.02)$.

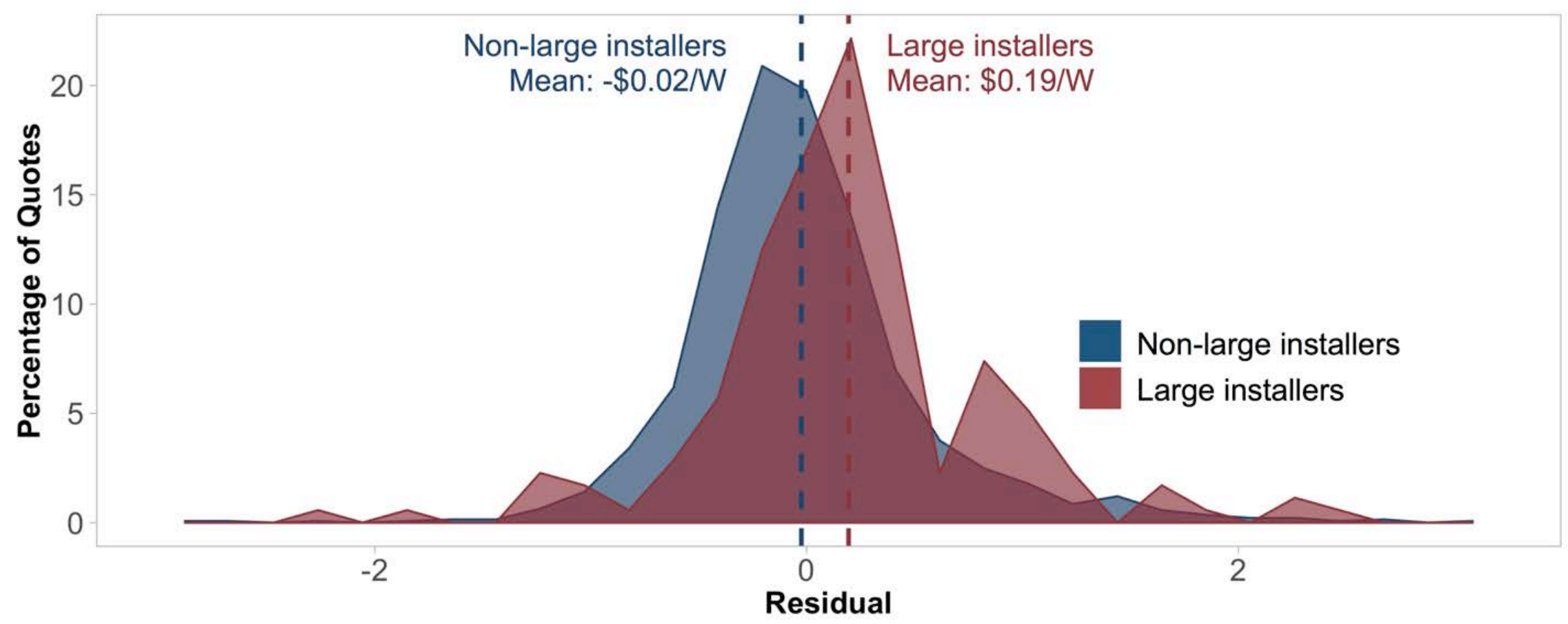

Residual Distributions for Large and Non-Large Installers 


\section{Results: Paired Difference Residuals Approach}

- The association between large installers and higher quote prices remains statistically significant after controlling for these factors.

- The average difference in residual values between paired large and nonlarge installer quotes is about $\$ 0.17 / \mathrm{W}(\mathrm{t}=6.3)$ without controlling for hardware, or about $\$ 0.21 / \mathrm{W}(t=6.9)$ when controlling for hardware.

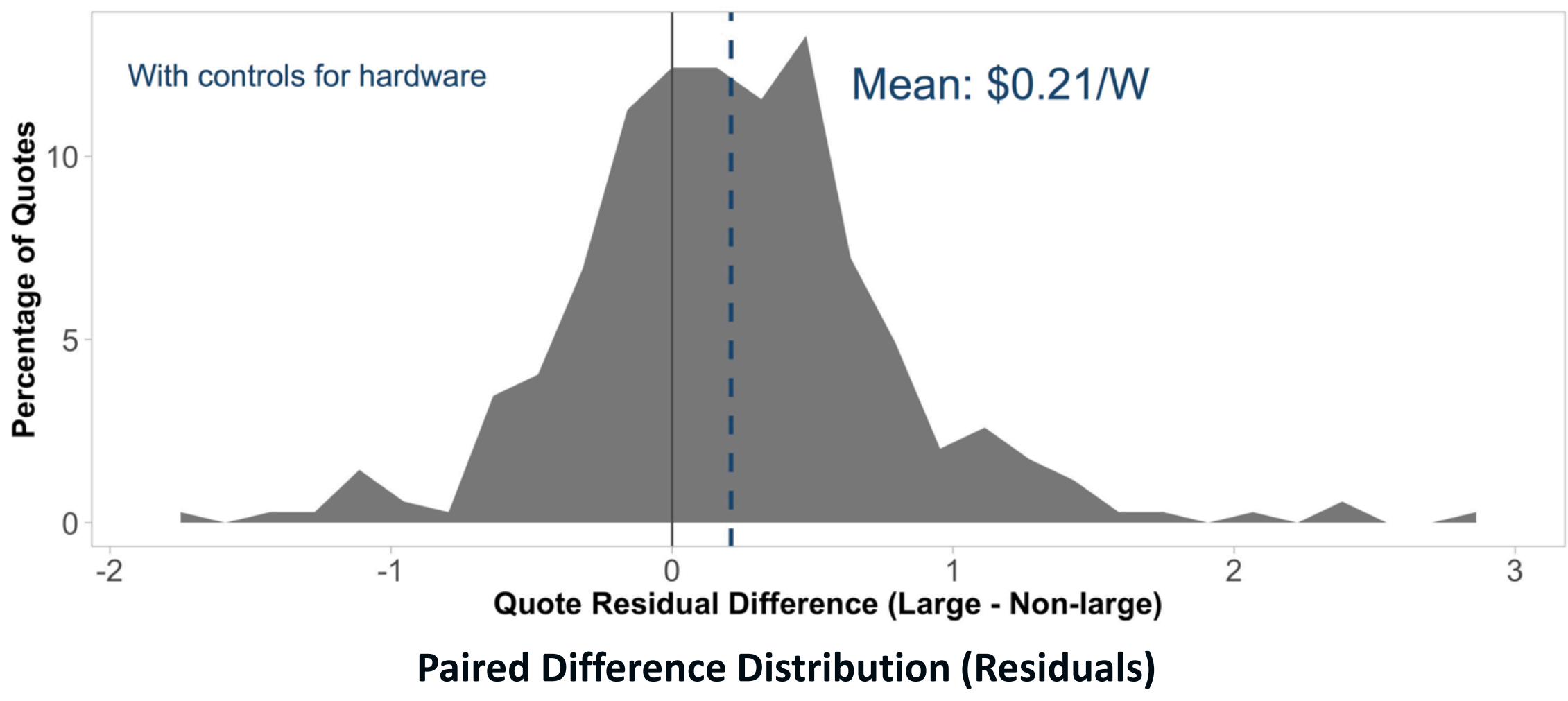




\section{Discussion}

- Our results suggest that low prices are not the primary value proposition of large installer systems.

- We discuss several hypotheses:

- Diseconomies of scale

- Market power

- Reputational values 
- Large installers may incur increasing customeracquisition costs from operating at a national scale.

- Large installers often offer additional products (e.g., leases, power-purchase agreements), that are not analyzed in our study.

- Large installers incur additional corporate costs to administer these alternative products.

- It is possible that large installers achieve lower prices in these alternative products. 


\section{Discussion: Market Power}

- Large installers may be better positioned to exercise market power than are non-large installers due to imperfect competition in the quote-collection process.

- Obtaining quotes can be costly, thus customers may settle for higher prices after obtaining a limited number of quotes.

- Large installers may be able to use large customeracquisition budgets to preempt competitors for the opportunity to bid a higher, but acceptable, price.

- Large installers may be able to use advertising and branding to differentiate their products and create a real or illusory perception of product quality. 


\section{Discussion: Market Power}

- Our results provide some support for the market power hypothesis: prices are lower on average for quotes made through EnergySage.

- Lower prices in EnergySage may reflect competitive pressures that reduce market power - the effect of increased price transparency on PV prices is an area for future research.

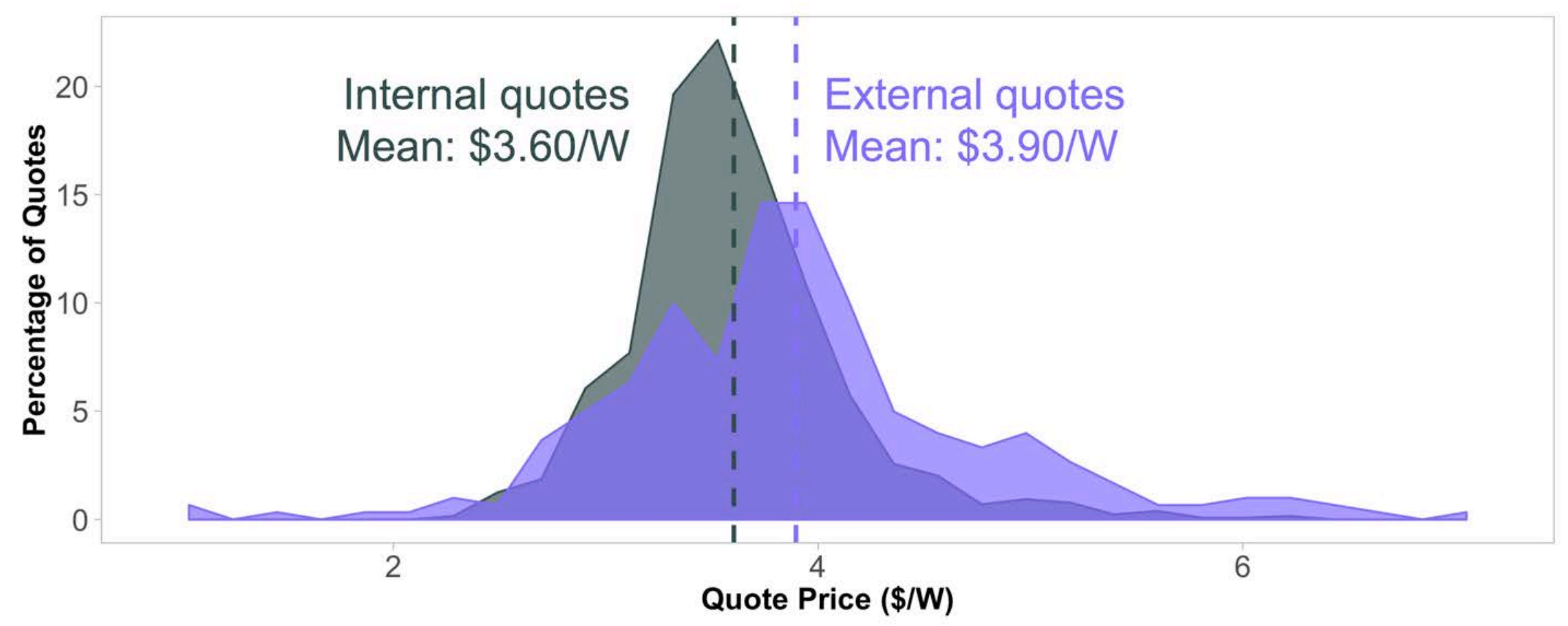

Quote Price Distributions for Internal (in EnergySage) and External Quotes 


\section{Discussion: Reputational Values}

- Customers may place additional reputational values on large installers and may be willing to pay higher prices to work with large installers.

- Customers may have more confidence that large companies will comply with contractual terms. 


\section{Conclusion}

- Firm size and market structure affect PV prices.

- Low prices are not the primary value proposition of large installers.

- Higher prices may reflect diseconomies of scale, market power, reputational values, or other factors.

- Increased price transparency and customer education may promote price reductions.

- Some customers may be willing to pay higher prices to work with large installers, but customers benefit from more transparent markets. 


\section{References}

O’Shaughnessy, E., R. Margolis. 2017. Using Residential Solar PV Quote Data to Analyze the Relationship Between Installer Pricing and Firm Size. NREL/TP-6A2068010. Golden, CO: NREL.

Full report is available at: http://www.nrel.gov/docs/fy17osti/68010.pdf

Barbose, G., and N. Darghouth. 2016. Tracking the Sun VIII: The Installed Price of Residential and Non-Residential Photovoltaic Systems in the United States. Berkeley, CA: Lawrence Berkeley National Laboratory.

Gillingham, K., H. Deng, R.H. Wiser, N. Darghouth, G. Nemet, G.L. Barbose, V. Rai, and C. Dong. 2016. "Deconstructing Solar Photovoltaic Pricing: The Role of Market Structure, Technology, and Policy." The Energy Journal 37(3):231-250.

Nemet, G., E. O'Shaughnessy, N.R. Darghouth, R.H. Wiser, G.L. Barbose, K. Gillingham, and V. Rai. 2017. "Characteristics of Low-Priced Photovoltaic Systems in the United States." Applied Energy 187:501-513.

Pless, J., R. Langheim, C. Machak, H. Hellow, and B. Sigrin. 2017. The PriceConcentration Relationship in Early Residential Solar Third-Party Markets. NREL/TP6A20-66784. Golden, CO: National Renewable Energy Laboratory. 


\section{Contact Information}

\section{Eric O'Shaughnessy}

eric.oshaughnessy@nrel.gov

303-275-4904
Robert Margolis

robert.margolis@nrel.gov

202-488-2222 